\title{
Therapeutic Use of Levothyroxine: A Historical Perspective
}

\author{
George J. Kahaly
}

The therapeutic use of levothyroxine (LT4) arose from observations made in the second half of the nineteenth century that linked the severe physical and cognitive defects of cretinism with an under-developed, or absent, thyroid gland. Improved outcomes for these subjects following empirical treatment with crude thyroid extracts spurred further research, and isolation, characterisation, and chemical synthesis of LT4 and triiodothyronine (T3) followed in the first half of the twentieth century. Treatment with LT4 + T3 combinations superseded the use of thyroid extracts from the 1960s onwards. The development of reliable and specific assays for thyroid hormones contributed greatly to understanding the importance and function of the thyroid and facilitated individualised treatment. Monotherapy with LT4 has been the mainstay of management of hypothyroidism from about 1970. Thyroid research is far from complete, however, and further research into several outstanding clinical issues will continue to shape LT4-based therapy in the future.

\section{Introduction}

In the opening chapter of this book, we consider the history of the therapeutic use of levothyroxine (LT4). Recognition of the therapeutic value of LT4 emerged from experience gained from, essentially, empirical administration by physicians of crude thyroid extracts to people with advanced sequelae of hypothyroidism [1-4]. These clinical experiments arose from early studies of people we would today describe as having severe congenital hypothyroidism. Accordingly, our story begins in the

\footnotetext{
G. J. Kahaly $(\varangle)$

Department of Medicine I, Johannes Gutenberg University (JGU) Medical Center, Mainz, Rheinland-Pfalz, Germany

e-mail: gkahaly@uni-mainz.de

(C) The Author(s) 2021

G. J. Kahaly (ed.), 70 Years of Levothyroxine,

https://doi.org/10.1007/978-3-030-63277-9_1
} 


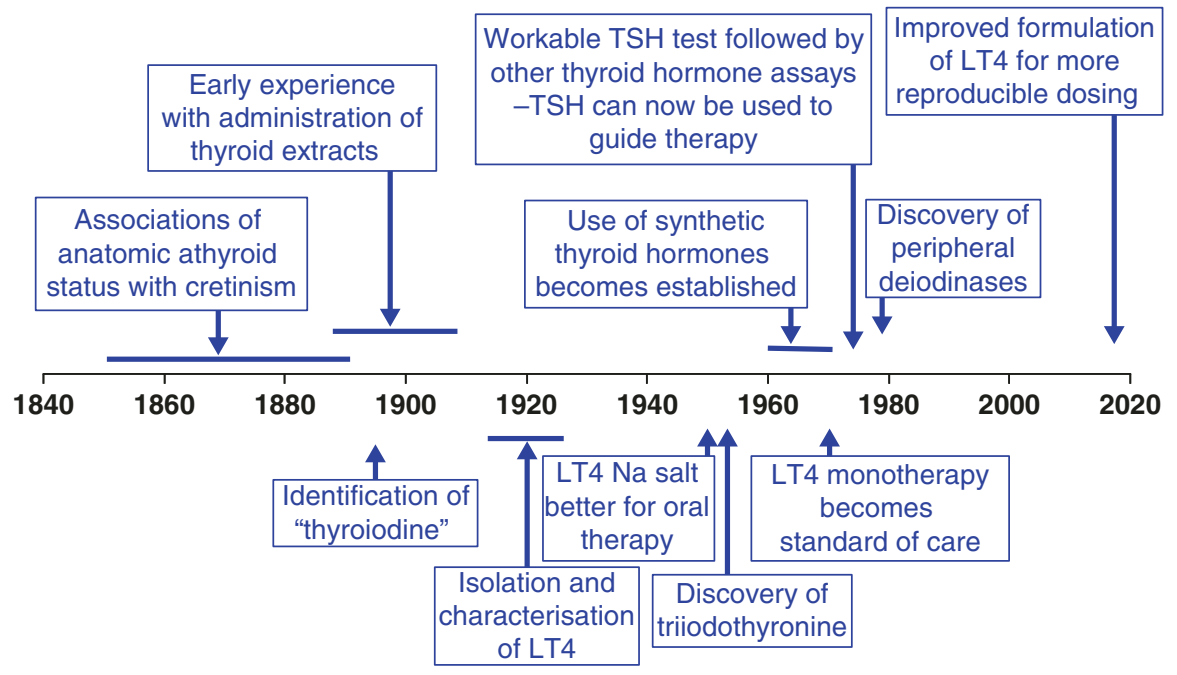

Fig. 1 Overview of key events relevant to the history of therapeutic use of levothyroxine for hypothyroidism. LT4 levothyroxine, Na sodium. Times are approximate

latter half of the nineteenth century, when these pioneering observations were being made, continues to the current management of hypothyroidism with LT4 and concludes with a brief review of outstanding research issues in this fast-moving field. Fig. 1 provides a timeline of key events along this journey, and these important advances are described below.

\section{Early Beginnings: Growing Understanding of the Thyroid}

\subsection{Cretinism, Goitre, and the Recognition of the Importance of the Thyroid Gland}

An appreciation of thyroid disease as a clinical entity began during the second half of the nineteenth century [1-4]. Briefly, sporadic, and widely spaced, reports in medical journals during this period described young, short-lived individuals presenting with growth retardation and "sporadic cretinism", which were found to be associated with minimal or absent thyroid tissue [5-7]. Such cases today would be described as congenital hypothyroidism, with the term "sporadic" used to differentiate them from "endemic cretinism", associated with goitre in iodine-deficient regions, which had been described centuries before. Later work during this period introduced the term, "myxoedema", to describe the anatomic appearance of the thyroid in these patients [1].

Surgery to remove goitre was being performed at this time, for example, to relieve symptoms of compression in the neck, despite a continuing lack of understanding of the function of the thyroid gland [8]. One contemporary study showed that removal of the entire thyroid led to the development of symptoms resembling those 
of "sporadic cretinism", and this observation led the author to restrict future surgeries to partial resection of the thyroid, with better outcomes [9]. Elsewhere, thyroidectomy in animals was shown to produce symptoms reminiscent of myxoedema, providing further strength to the association of athyroid status with "sporadic cretinism" [10]. These extreme cases were the first demonstrations of the pathophysiological importance of the thyroid gland to healthy development although not based on any understanding of the function of the thyroid. Other experiments conducted at this time noted that thyroidectomy was lethal to dogs, but that the health of the animals could be preserved temporarily by grafting the thyroid elsewhere in the animals' bodies [11]. Even so, it was assumed that the function of the thyroid was allied to detoxification of the blood, rather than to an independent and specific endocrine function [3].

\subsection{An Endocrine Function for the Thyroid Gland}

It had been suggested in about 1820 (soon after the characterisation of iodine as a chemical element) that the limited efficacy of dietary ingestion of foodstuffs such as sponges or seaweed in the diet (an ancient, traditional remedy for goitre) was connected to the presence of iodine in these items [12]. The first attempts at iodine supplementation, either using a tincture of iodine, or with iodised salt, followed during the following decade [4]. A correlation between scarcity of iodine in the environment and an increased prevalence of goitre was published some 30 years later [13]. This was followed by further trials of iodine supplementation in three Departments of France where problems with goitre were especially severe. These were largely successful, and it was reported in 1869 that about $80 \%$ of cases of goitre responded favourably to treatment [14]. Several problems with the conduct of these trials led to their early cessation; these included an excessively high dose of iodine (which commonly caused hyperthyroidism in adult recipients), continuing scepticism among the medical profession, and reluctance to participate by citizens who feared that curing their sons' goitres would remove an obstacle to their being conscripted for military service [4].

From about 1890 onwards, physicians were experimenting with the administration of thyroid extracts (orally or subcutaneously) to people with myxoedema [3]. These early clinical studies were generally successful; one patient with advanced myxoedema that developed in middle age was treated with subcutaneous injections of sheep thyroid extract and lived for 28 years before dying of heart failure at age 74 years [15]. The author, the British physician, George Murray, concluded that the thyroid is "purely an internal secretory gland", that the "functions of this gland in man can be fully and permanently carried on by the continued supply of thyroidal hormones", and, crucially, that "duration of life need not be shortened by atrophy of the thyroid gland provided this substitution treatment is fully maintained" [15]. These concepts underpin the management of hypothyroidism to this day. Interestingly, this represents an early example of the seeking of informed consent for a trial of a therapeutic agent: the physician had explained the experimental nature of the treatment and had sought and obtained the patient's consent. A review of 100 cases of patients with myxoedema and cretinism, published in 1893 attests to 
Fig. 2 Chemical structures of thyroid hormones
Thyroxine (T4)
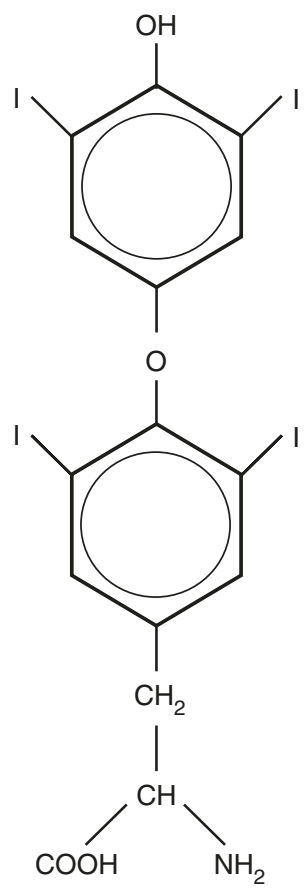

Triiodothyronine (T3)
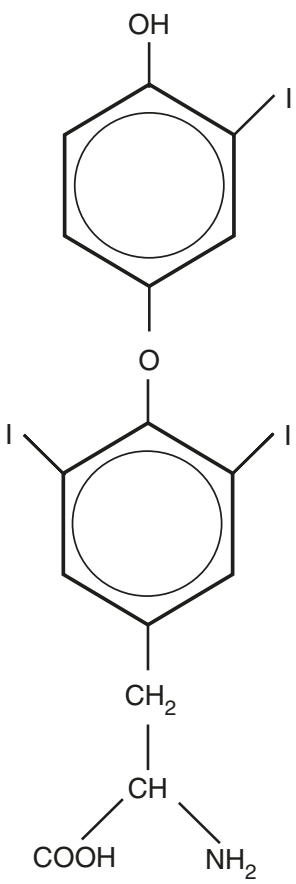

the remarkable success attributed to this treatment, using phrases such as "complete transformation" and "the patient has ceased to be a patient" [16].

The discovery in 1895 of a substance containing high concentrations of iodine within the thyroid gland ("thyroiodine") was therefore of considerable interest in unifying concepts relating to hypothyroidism and iodine, and the role of the thyroid as an endocrine organ [17]. The substance that would come to be known as thyroxine (T4) was isolated in the USA in 1915 and fully chemically characterised in 1926 (and published the following year [18]). It was also established that LT4 had greater biological activity than a racemic mixture. The discovery of triiodothyronine (T3) as a "normal constituent of the organic iodine fraction of the plasma" of subjects with normal thyroid function or hyperthyroidism followed in 1952 [19]. Fig. 2 shows the chemical structures of these hormones.

\section{Towards the Modern Era in the Management of Hypothyroidism}

\subsection{Introduction of Chemically Synthesised Thyroid Hormones}

The early attempts at thyroid replacement via "organ therapy" (as the practice of administration of extracts of animal organs became known), described briefly in the previous section, were taking place at a time when this practice was becoming 
widespread in the management of other conditions [20]. For example, a report by a leading physician in France on the allegedly rejuvenating effects of self-injection with animal testicular extracts led to great enthusiasm for this practice among other physicians. Eventually, a growing association with widespread quackery in the hands of other practitioners led to a general discrediting of the principle of "organotherapy" $[20,21]$.

Nevertheless, although early practitioners such as Murray switched from injected to oral preparations of thyroid extracts, mainly to prevent serious systemic adverse reactions and abscesses and other problems at the local injection site, it was some time before chemically synthesised LT4 entered into clinical practice. This was partly due to limitations of chemically synthesised LT4, which was produced as an acid and had limited bioavailability before the synthesis of a sodium salt of in 1949 [21]. This preparation entered clinical use in that year in the USA, and entered clinical use in Europe some years later.

It took considerable time for synthesised LT4 to become the mainstay of treatment for hypothyroidism, however. Indeed, the use of products based on thyroid extracts did not decline markedly until the latter part of the 1960s, due to difficulties with reproducibility of their biological action and limited storage life [2, 22]. Desiccated thyroid products are available for therapeutic use to this day, despite the currently high regulatory standards for manufacture of LT4 tablets, which ensure reproducibility of day-to-day dosing (see below). Such preparations have persisted, despite lack of convincing objective evidence of superior efficacy in controlling hypothyroid symptoms [23]. There is an enduring perception that these products are a more "natural" treatment than the pharmaceutical preparation [24] although the balance of T4 and T3 levels in animals is not the same as that in humans, and preparations contain excipients and other non-natural substances, as does any pharmaceutical [22].

\subsection{Monotherapy or Combination Therapy?}

In the 1960s, the use of oral combinations of LT4 and T3 became widely used in the management of hypothyroidism, due to an assumption that delivery of both thyroid hormones would mimic the natural function of the thyroid gland [25]. In addition, as thyroid extracts were essentially the reference product for clinical trials at this time, studies comparing thyroid extracts and LT4 + combinations gave broadly similar clinical results. However, the pharmacokinetic half-life of T3 is much shorter than that of T4 [26]. In addition, it was discovered in the 1970s that about $80 \%$ of T3 in peripheral tissues is derived from local conversion from T4 by local deiodinases, rather than from the thyroid [27]. Moreover, too high a dose of $\mathrm{T} 3$ results in symptoms of hyperthyroidism, complicating the delivery of combination therapy [26]. A series of clinical trials from 1970 onwards compared T4 + T3 combination therapy with monotherapy with LT4 in hypothyroid patients, and these studies have established monotherapy with LT4 as the standard of care for managing hypothyroidism for the vast majority of patients [28, 29]. Today, LT4 is the most commonly prescribed medication in the USA [30]. A fuller account of the current 
status of and prospects for LT4 + T3 combination therapy is given in the chapter, "Pharmacodynamic and Therapeutic Actions of Levothyroxine" of this book.

\subsection{Technological Advances: Better Assays of Thyroid Function}

The introduction of pharmaceutical preparations of synthetic thyroid hormones and establishment of monotherapy with LT4 as the standard of care for hypothyroidism opened up a prospect of delivery of stable, reproducible therapy tailored to the needs of the individual patient. To achieve this, it was necessary to measure circulating levels of thyroid hormones accurately and reproducibly. In the 1950s, the only thyroid hormone test available (the protein bound iodine assay) provided an indirect measurement of serum total T4; today, sensitive and specific assays exist for free and bound T4 or T3, thyrotropin (thyroid-stimulating hormone; TSH), thyroglobulin (a precursor of thyroid hormones), and a range of proteins that bind thyroid hormones in the circulation, based on radioimmunoassay or liquid chromatographytandem mass spectrometry (LC-MS/MS) technology [31]. These assays made it possible to accurately determine the thyroid status of patients with all degrees of severity of thyroid dysfunction and facilitated a leap in our understanding of the physiology of the thyroid gland.

The discovery of a workable TSH test in the mid 1970s was a key development in the diagnosis and management of hypothyroidism. Levels of T4 and T3 are low in the setting of hypothyroidism, and the pituitary responds by increasing the secretion of TSH in an attempt to correct this, leading to an abnormally high TSH level [25]. The relationship between levels of T4 and TSH is not linear, however, as decreasing the level of T4 by half results in an increase in the TSH level of as much as 100-fold [32]. Large changes in TSH are clearly more amenable to accurate measurement than the accompanying relatively much smaller changes in T4. Accordingly, the management of hypothyroidism is now based on normalisation of the circulating TSH level to within a reference range for this parameter derived from a healthy population [33-35].

\subsection{Recent Developments in Levothyroxine Therapy}

LT4 was introduced into the therapeutic armamentarium in the USA in the 1950s without a requirement for regulatory oversight. This situation is very different today, with increasingly close regulatory attention paid to the standards of manufacture of LT4 products. This has led to the development of new formulations of LT4, with more accurate and reproducible dosing, designed to improve the accuracy and reproducibility of exposure to LT4 for a patient taking this medication. A full account of this new formulation is given in the following chapter [36]. 


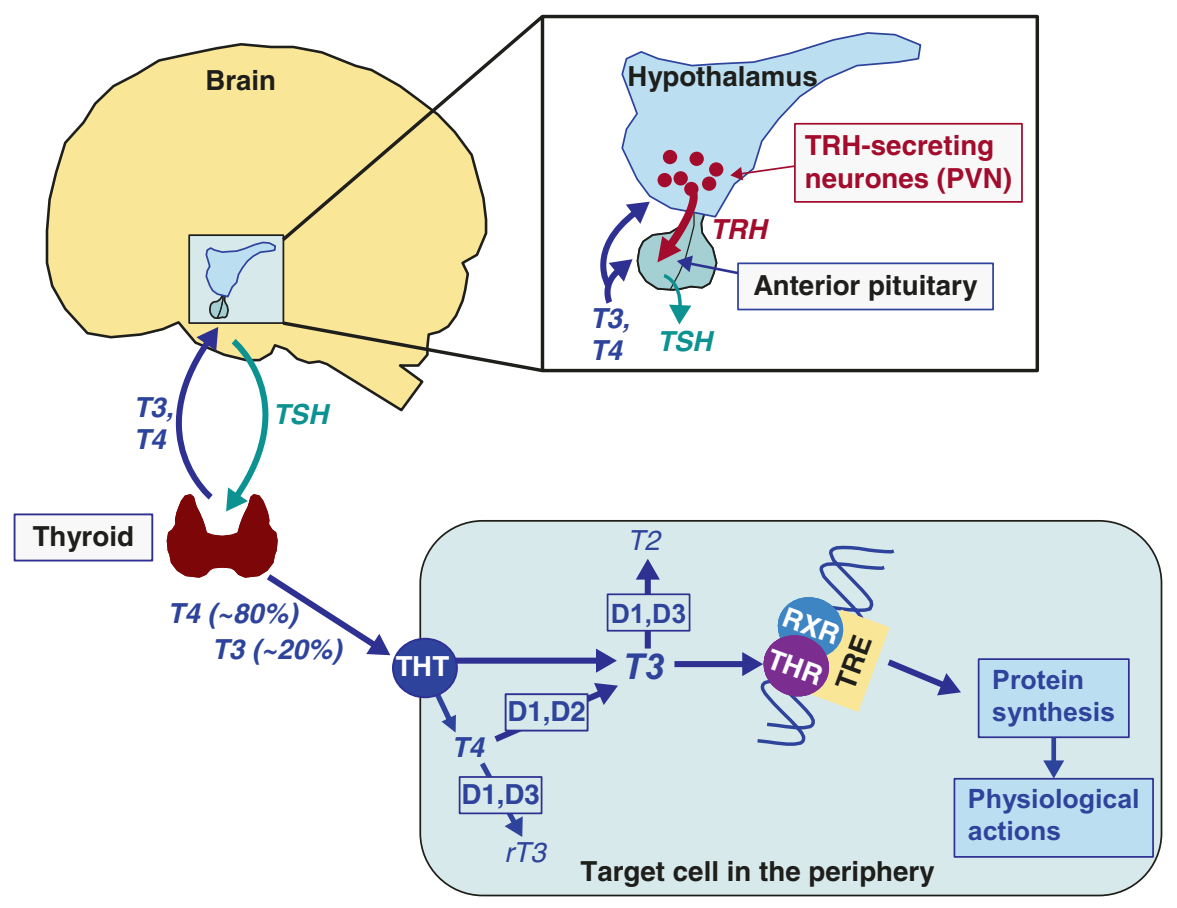

Fig. 3 Simplified schematic overview of the principal physiological systems involved in thyroid hormone homeostasis. D1/2/3 deiodinase 1/2/3, T2 diiodothyronine, $r T 3$ reverse triiodothyronine (inactive), $R X R$ retinoic acid receptor, TRE thyroid hormone response element, $T 3$ triiodothyronine, $T 4$ thyroxine, THR thyroid hormone receptor, TRH thyrotropin-releasing hormone, TSH thyrotropin (thyroid-stimulating hormone), $P V N$ periventricular nucleus (of the hypothalamus)

\section{Where We Stand Today}

\subsection{A Fuller (But Incomplete) Understanding of Thyroid Hormone Homeostasis}

Our understanding of the complex homeostatic mechanisms underlying the regulation of thyroid hormones and their actions continues to increase. Fig. 3 provides an overview of the principal systems involved [37-40]. Briefly, inputs from physiological processes all around the body are integrated within the hypothalamus. Neurones within the periventricular nucleus of the hypothalamus secrete higher or lower amounts of thyrotropin-releasing hormone (TRH), depending on current physiological needs, which acts on the nearby anterior pituitary gland to promote secretion of TSH, the principal regulator of thyroid hormone secretion. Most (about $80 \%$ ) of the thyroid hormone secreted by the thyroid in response to TSH is T4, with T3 making up the remainder. T3 and T4 feedback to the hypothalamus and pituitary to inhibit further production of TSH: thus, hypothyroidism is characterised by high levels of TSH, due to lack of inhibition of TSH secretion by thyroid-derived T4.

In the peripheral tissues, thyroid hormone-sensitive target cells of the body take up $\mathrm{T} 4$ and T3 via transmembrane carriers. T4 is converted to T3 within cells by specific 
deiodinases, which also deactivate thyroid hormones, by converting T4 into reverse T3, and T3 into diiodothyronine. A complex of T3, its intracellular thyroid hormone receptor, and the thyroid hormone-responsive element alters the transcription of a large number of genes to mediate the pleiotropic physiological actions of thyroid hormones.

It is clear that the regulation of thyroid hormone function takes place on a number of distinct levels, including during integration of signal inputs in the hypothalamus and secretion of TRH, feedback inhibition of TSH release by T4, and, locally, by control of the deiodinases that determine the prevailing level of functionally active T3. Other chapters of this book, especially chapters, "Administration and Pharmacokinetics of Levothyroxine", and "Pharmacodynamic and Therapeutic Actions of Levothyroxine" will touch on specific aspects of thyroid hormone homeostasis relevant to their subjects of interest.

\subsection{Unresolved Issues and Current Research Questions}

Research continues into the management of hypothyroidism, and Table 1 highlights several important issues that remain unresolved [28, 32, 41-47]. Resolution of these

Table 1 Outstanding research questions concerning the management of hypothyroidism and therapeutic use of LT4

\begin{tabular}{l|l}
\hline Clinical issue & Outstanding research questions \\
Subclinical & $\begin{array}{l}\text { This term describes a mild elevation of TSH where the thyroid-derived } \\
\text { hormones are within their normal reference ranges. The current consensus is } \\
\text { that most people with subclinical hypothyroidism, and a baseline serum } \\
\text { TSH below 10 mU/L, should not receive treatment with LT4 [41]. However, } \\
\text { a trial of LT4 may be given to non-elderly patients with symptoms, risk } \\
\text { factors for atherosclerosis and coronary heart disease, e.g. hyperlipidaemia, } \\
\text { hypertension, diabetes mellitus, and mild elevation of TSH, according to } \\
\text { European guidelines [42]. }\end{array}$ \\
\hline $\begin{array}{l}\text { TSH reference } \\
\text { ranges }\end{array}$ & $\begin{array}{l}\text { Debate continues as to whether the upper reference limit for serum TSH } \\
\text { should be reduced [32]. }\end{array}$ \\
\hline Cardiovascular & $\begin{array}{l}\text { People with foremost acute cardiovascular disease have reduced levels of } \\
\text { thyroid hormones, particularly T3, on average, and this has been associated } \\
\text { with increased risk of adverse clinical outcomes in observational studies } \\
\text { [45]. Experts in the field have called for clinical evaluations of thyroid } \\
\text { hormone treatment (with LT4 and/or T3) in this population [46]. More data } \\
\text { are required on the association between subclinical hypothyroidism and the } \\
\text { risk of adverse cardiovascular outcomes [41, 42]. }\end{array}$ \\
\hline $\begin{array}{l}\text { Unwell patients } \\
\text { with well- } \\
\text { controlled TSH }\end{array}$ & $\begin{array}{l}\text { Some patients report symptoms reminiscent of thyroid dysfunction despite } \\
\text { well-controlled thyroid hormones [47]. Many of these symptoms will be } \\
\text { found to relate to a non-thyroid cause, and can be eliminated through careful } \\
\text { patient workup [47]. However, patients may have their own individual set } \\
\text { point for thyroid hormone levels, and the delivery of individualised therapy } \\
\text { for this population requires further study [32]. }\end{array}$ \\
\hline $\begin{array}{l}\text { LT4 monotherapy, } \\
\text { or LT4 + T3? }\end{array}$ & $\begin{array}{l}\text { Current guidance does not support the use of combinations of LT4 and T3 to } \\
\text { correct hypothyroidism (see text). However, some experts support the use of } \\
\text { a trial of LT4 + T3 where patients' symptoms have not been controlled by } \\
\text { TSH-optimised LT4 monotherapy and cannot be explained by other } \\
\text { conditions [28]. Combination therapy with thyroid hormones remains } \\
\text { within the research domain, for now. }\end{array}$ \\
\hline
\end{tabular}


clinical issues will influence the future management of hypothyroidism, including the therapeutic use of LT4.

\section{Conclusions}

The history of hypothyroidism and its management spans the golden age of clinical research, from empirical medical and surgical treatments unencumbered by understanding of thyroid physiology in the nineteenth century to individualised, TSH-guided treatment with LT4 today. Along the way, many clinical and experimental studies, enhancements in technology, and improved LT4 preparations have increased greatly our ability to deliver optimal care for hypothyroidism, based on the therapeutic administration of LT4.

\section{References}

1. Lindholm J, Laurberg P. Hypothyroidism and thyroid substitution: historical aspects. J Thyroid Res. 2011;2011:809341.

2. McAninch EA, Bianco AC. The history and future of treatment of hypothyroidism. Ann Intern Med. 2016;164:50-6.

3. Ahmed AM, Ahmed NH. History of disorders of thyroid dysfunction. East Mediterr Health J. 2005;11:459-69.

4. Zimmermann MB. Research on iodine deficiency and goiter in the 19th and early 20th centuries. J Nutr. 2008;138:2060-3.

5. Curling TB. Two cases of absence of the thyroid body, and symmetrical swellings of fat tissue at the sides of the neck, connected with defective cerebral development. Med Chir Trans. 1850;33:303-6.

6. Fagge CH. On sporadic cretinism, occurring in England. Med Chir Trans. 1871;54:55-169.

7. Gull WW. On a cretinoid state supervening in adult life in women. Trans Clin Soc Lond. $1874 ; 7: 180-5$.

8. Hannan SA. The magnificent seven: a history of modern thyroid surgery. Int J Surg. 2006;4:187-91.

9. Kocher T. Ueber Kropf exstirpation und ihre Folgen. Arch Klin Chir. 1883;29:254-335.

10. Horsley V. On the function of the thyroid gland. Proc R Soc Lond. 1885;38:5-7.

11. Schiff M. Résumé d'une nouvelle série d'expériences sur les effets de l'ablation des corps thyroîdes. Rev Med Suisse Romande. 1884;4:425-45.

12. Coindet JF. Nouvelles recherches sur les effets de l'iode et sur les précautions à suivre dans le traitement du goître par ce nouveau remède. Ann Chim Phys. 1821;16(Ser. 2):345-56.

13. Chatin A. Recherches sur l'iode des eaux douces; de la présence de ce corps dans les plantes at les animaux terrestes. C R Hebd Séances Acad Sci. 1851;31:280-3.

14. Goitre in savoy. Lancet. 1869;94:518.

15. Murray GR. The life-history of the first case of myxoedema treated by thyroid extract. Br Med J. 1920;1:359-60.

16. Beadles CF. The treatment of myxoedema and cretinism, being a review of the treatment of these diseases with the thyroid gland, with a table of 100 published cases. J Ment Sci. 1893;39:509-36. 
17. Baumann E. Ueber das normale Vorkommen von Jod im Thierkörper. Hoppe-Seyler's Z Physiol Chem. 1895;21:319-30.

18. Harington CR, Barger G. XXIII. Chemistry of thyroxine. III. Constitution and synthesis of thyroxine. Br Med J. 1927;21:169-83.

19. Gross J, Pitt-Rivers R. The identification of 3:5:3'-L-triiodothyronine in human plasma. Lancet. 1952;259:439-41.

20. Bernhardt MS. Organotherapy. JAMA Dermatol. 2013;149:1366.

21. Slater S. The discovery of thyroid replacement therapy. Part 3: a complete transformation. J R Soc Med. 2011;104:100-6.

22. American Thyroid Association. Thyroid hormone treatment. Available at http://www.thyroid. org/thyroid-hormone-treatment/. Accessed Jul 2020.

23. Hoang TD, Olsen CH, Mai VQ, Clyde PW, Shakir MK. Desiccated thyroid extract compared with levothyroxine in the treatment of hypothyroidism: a randomized, double-blind, crossover study. J Clin Endocrinol Metab. 2013;98:1982-90.

24. American Thyroid Association. Clinical thyroidology for patients. Hypothyroidism. Desiccated thyroid extract vs levothyroxine in the treatment of hypothyroidism. Available at https://www.thyroid.org/patient-thyroid-information/ct-for-patients/vol-6-issue-8/vol-6-issue8-p-3/. Accessed Jul 2020.

25. Kansagra SM, McCudden BSCR, Willis MS. The challenges and complexities of thyroid hormone replacement. Lab Med. 2010;41:338-48.

26. Irizarry I. Thyroid hormone toxicity. Medscape drugs and diseases. Available at https://emedicine.medscape.com/article/819692-overview. Accessed Jul 2020.

27. Luongo C, Dentice M, Salvatore D. Deiodinases and their intricate role in thyroid hormone homeostasis. Nat Rev Endocrinol. 2019;15:479-88.

28. Dayan C, Panicker V. Management of hypothyroidism with combination thyroxine (T4) and triiodothyronine (T3) hormone replacement in clinical practice: a review of suggested guidance. Thyroid Res. 2018;11:1.

29. Wiersinga WM, Duntas L, Fadeyev V, Nygaard B, Vanderpump MP. 2012 ETA guidelines: the use of L-T4 + L-T3 in the treatment of hypothyroidism. Eur Thyroid J. 2012;1:55-71.

30. Frellick M. Top-selling, top-prescribed drugs for 2016. Medscape. 2 Oct 2017. Available at https://www.medscape.com/viewarticle/886404. Accessed Jul 2020.

31. Spencer CA. Assay of thyroid hormones and related substances. Endotext [Internet]. Available at https://www.ncbi.nlm.nih.gov/books/NBK279113/. Accessed Jul 2020.

32. Razvi S, Bhana S, Mrabeti S. Challenges in interpreting thyroid stimulating hormone results in the diagnosis of thyroid dysfunction. J Thyroid Res. 2019;2019:4106816.

33. Okosieme O, Gilbert J, Abraham P, et al. Management of primary hypothyroidism: statement by the British Thyroid Association Executive Committee. Clin Endocrinol (Oxf). 2016;84:799-808.

34. National Institute for Health and Care Excellence. Clinical knowledge summaries. Hypothyroidism. Last revised in Jun 2018. Available at https://cks.nice.org.uk/hypothyroidism. Last accessed Jul 2019.

35. Jonklaas J, Bianco AC, Bauer AJ, et al. Guidelines for the treatment of hypothyroidism: prepared by the American Thyroid Association Task Force on Thyroid Hormone Replacement. Thyroid. 2014;24:1670-751.

36. Lipp HP, Hostalek U. A new formulation of levothyroxine engineered to meet new specification standards. Curr Med Res Opin. 2019;35:147-50.

37. Visser TJ. Cellular uptake of thyroid hormones. Endotext [Internet]. Available at https://www. ncbi.nlm.nih.gov/books/NBK285565/. Accessed Jul 2020.

38. Ortiga-Carvalho TM, Sidhaye AR, Wondisford FE. Thyroid hormone receptors and resistance to thyroid hormone disorders. Nat Rev Endocrinol. 2014;10:582-91.

39. Nillni EA. Regulation of the hypothalamic thyrotropin releasing hormone (TRH) neuron by neuronal and peripheral inputs. Front Neuroendocrinol. 2010;31:134-56. 
40. Shahid MA, Ashraf MA, Sharma S. Physiology, thyroid hormone. Stat Pearls [Internet]. 2018. Available at https://www.ncbi.nlm.nih.gov/books/NBK500006/. Accessed Jul 2020.

41. Bekkering GE, Agoritsas T, Lytvyn L, et al. Thyroid hormones treatment for subclinical hypothyroidism: a clinical practice guideline. BMJ. 2019;12006:365.

42. Pearce SH, Brabant G, Duntas LH, et al. 2013 ETA guideline: management of subclinical hypothyroidism. Eur Thyroid J. 2013;2:215-28.

43. Chaker L, Baumgartner C, den Elzen WP, et al. Thyroid function within the reference range and the risk of stroke: an individual participant data analysis. J Clin Endocrinol Metab. 2016;101:4270-82.

44. Åsvold BO, Vatten LJ, Bjøro T, et al. Thyroid function within the normal range and risk of coronary heart disease: an individual participant data analysis of 14 cohorts. JAMA Intern Med. 2015;175:1037-47.

45. Razvi S, Jabbar A, Pingitore A, et al. Thyroid hormones and cardiovascular function and diseases. J Am Coll Cardiol. 2018;71:1781-96.

46. Razvi S. Novel uses of thyroid hormones in cardiovascular conditions. Endocrine. 2019;66:115-23.

47. Centanni M, Benvenga S, Sachmechi I. Diagnosis and management of treatment-refractory hypothyroidism: an expert consensus report. J Endocrinol Investig. 2017;40:1289-301.

Open Access This chapter is licensed under the terms of the Creative Commons Attribution 4.0 International License (http://creativecommons.org/licenses/by/4.0/), which permits use, sharing, adaptation, distribution and reproduction in any medium or format, as long as you give appropriate credit to the original author(s) and the source, provide a link to the Creative Commons license and indicate if changes were made.

The images or other third party material in this chapter are included in the chapter's Creative Commons license, unless indicated otherwise in a credit line to the material. If material is not included in the chapter's Creative Commons license and your intended use is not permitted by statutory regulation or exceeds the permitted use, you will need to obtain permission directly from the copyright holder.

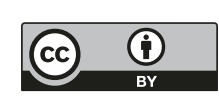

